\title{
EDITORIAL
}

\section{Mentorship-challenges ahead}

\section{Sanjay N Jain}

Editor-in-Chief, The Indian Journal of Radiology and Imaging, Prince Aly Khan Hospital, Aga Hall, Nesbit Road, Mazagaon, Mumbai - 400 010, Maharashtra, India. E-mail: editor@ijri.org

Dear colleagues,

As the famous shloka from Vishvasara Tantra on Guru states,

"Gurur Brahma, Gurur Vishnu, Gururdevo Maheshwaraha, Guru Shakshat, Para Brahma, Tasmai Shri, Gurave Namah," meaning "Guru is verily the representative of Brahma, Vishnu, and Shiva. He creates, sustains knowledge, and destroys the weeds of ignorance; hence, I salute such a guru." $[1]$

I would like to take you through the path of basics in this editorial, as regards the journey of a radiologist from generation to generation. The foundation stone of the path which we all have been traveling has been laid by our elders; the baton of the same, after our journey, has to be passed on to the next generation radiologists, who would further carry the same down the line. This cannot be done on the retiring day, when we wind up the practice for the next generation to begin; rather, it has to be started and actively nurtured during our time of practice. The very edifice of our profession lies on the indelible fact that at the right time, radiology has to have a smooth and subtle transit from one generation to the other. At no point in time should it be crystallized, making it impossible to sail further.

Student mentoring can be seen as a process wherein the mentor acts and provides impetus for learning, rather than acting as a "teacher" per se. ${ }^{[2]}$ The student has to learn on his or her own, while the mentor would provide the much needed support system to help clarify the crux areas warranting the student to concentrate upon, or be available to students who need clarity on certain gray areas. The mentor need not be a pracademic, but can be the one who gives students an insight into the outer world. The very aspect of mentoring is to help a student begin his/her journey well. One aspect which needs to be understood here

\begin{tabular}{|l|l|}
\hline \multicolumn{2}{|c|}{ Access this article online } \\
\hline Quick Response Code: & Website: \\
\hline & www.ijri.org \\
& DOI: \\
\hline & $10.4103 / 0971-3026.134366$ \\
\hline
\end{tabular}

is that when a student qualifies as a radiologist, he or she is as good as a newborn child with minimal requirements, enabling it to take birth; the real growth happens later. Flexibility during child birth enables the child to come to the external world; from that moment, the whole life building journey begins.

In pursuit of the same, an important aspect that the radiologists of our generation need to keep in mind is to help play the role of a mentor in helping the students learn about the nuances and techniques the profession seeks to offer, over a period in time, by giving them inputs, as warranted.

Our country has had the immortal Guru-Shishya tradition of education wherein the guru, in the process of imparting knowledge to his disciples, transfers, over a period in time, all the skills that he has acquired, in pursuit of helping to continue the knowledge chain. The disciple, in his lifetime, passes the knowledge to the succeeding generations, thereby helping the shishya also reach the stage of a guru in course of time, and so forth.

The foundation of any profession is the student community, which would eventually qualify to be a member in due course. This brings us to the most difficult situation a student would face, and that would be as to how to handle the issues which pesters one during the course of the radiology residency and at the very entry to the practical world outside.

One very important aspect which needs to be noted here is that the whole process of mentoring is to make a student realize his or her inclusive potential, encompassing the pitfalls, errors, mistakes, and any other aspect that would impede the student from proceeding further and to help the student overcome that in the said direction, rather than visualizing the whole process as a pursuit of creating a "110\% ever successful super radiologist."

And looking at the other side, who could become a mentor or who can call oneself to be a mentor? It can be the one who has subject knowledge and expertise, alongside empathizing with the students by looking from their perspective and guiding them when needed and be available, which is a very difficult aspect these days, given the busy practice in vogue. The mentor in his or her 
quest should allow the student to fail and rise, rather than admonishing when such failures occur and demoralizing the students. The mentor is keenly visualized as the one who can act as a connection with the practical world of the profession, helping the students look forward to what can they may come in contact with. ${ }^{[3]}$

The underlying need for concentration here is purely connected to the students of radiology in India since those who pursue their PG in radiology overseas have, by and large, been exposed to a larger perspective contact wise, owing to a plethora of universities offering radiology as an option, which, in contrast, has not permeated to that extent still in India. Majority of the guidelines or the strategies are primarily concerning the western world where the modalities and circumstances are quite different; what we need to see is the strategy to develop the Indian version of the same and help the students here.

The significance is also primordial since the area of concentration cannot be confined to the mentees of metropolitan city-based medical colleges alone; it has to pervade into the academic institutions in the rural belts as well. That is when the holistic picture of mentor-mentee relationship would survive and thrive. For students who can avail mentoring, it would ease their situation a bit, in sharp contrast to those who do not get exposed to mentoring; but they cannot be left in the lurch. A cohesive and holistic approach warrants applicability's success.
Academicians can be of immense help in this regard as they are with the students throughout; but even consultants can chip in by making themselves available as and when needed. The overall picture would be incomplete without the pivotal intervention of IRIA in helping alleviate the situation for the benefit of the profession in times to come; that is, when we can comfortably state that radiologists would come and go, but the profession of radiology remains forever.

One such mentor, Surg Capt (Dr.) IK Indrajit, Associate Editor, IJRI, was lost recently by the profession (30 April, 2014). As an Editor, he was in charge of "Computers in radiology" and "Web reviews," and he gave various inputs as an excellent reviewer. A thorough pracademic, the editorial office will miss him for generations to come.

As an old Chinese saying goes, "The journey of a thousand miles must begin with a single step."

\section{References}

1. http://en.wikipedia.org/wiki/User: Gurubrahma.

2. Slanetz PJ, Boiselle PM. Mentoring matters. AJR Am J Roentgenol 2012;198:W11-2.

3. Mainiero MB. Mentoring radiology residents: Why, who, when, and how. J Am Coll Radiol 2007;4:547-50.

Cite this article as: Jain SN. Mentorship-challenges ahead. Indian J Radiol Imaging 2014;24:95-6.

Source of Support: Nil, Conflict of Interest: None declared. 